\title{
ECONOMIA CRIATIVA: OPORTUNIDADES E GARGALOS PARA O SEU FORTALECIMENTO NA CIDADE DO RIO DE JANEIRO
}

CREATIVE ECONOMY: OPPORTUNITIES AND BOTTLENECKS FOR ITS STRENGTHNING IN THE CITY OF RIO DE JANEIRO

\section{RESUMO}

O artigo trata da relação entre o campo da economia criativa e sua crescente associação aos debates sobre desenvolvimento, especialmente nas escalas local e regional. O objetivo principal é identificar as oportunidades e os gargalos para o fortalecimento da economia criativa na cidade do Rio de Janeiro por meio da análise dos dados secundários de diversas bases estatísticas utilizadas na construção do Índice de Desenvolvimento Potencial da Economia Criativa (IDPEC), o qual foi aplicado a todas as capitais do Brasil. Além dessa análise mais centrada na capital, o artigo também apresenta um panorama da economia criativa no estado e a sua concentração na capital. Os resultados, por um lado, revelam a importância das atividades criativas na economia da cidade do Rio de Janeiro, as quais podem ser mobilizadas como indutoras do desenvolvimento, todavia, por outro lado, identificamos gargalos a serem superados em fatores cruciais para o fortalecimento da economia criativa, especialmente os que se relacionam com a educação, atratividade da cidade do Rio de Janeiro e políticas de apoio a cultura.

Palavras-chave: Economia criativa. Desenvolvimento. Rio de Janeiro. Índice de Desenvolvimento Potencial da Economia Criativa.

\section{ABSTRACT}

The article deals with the relationship between creative economy and its increasing association with development debates, especially at local and regional scales. The main objective is to identify opportunities and bottlenecks for strengthening the creative economy in the city of Rio de Janeiro through the analysis of secondary data collected from various statistical bases used in the construction of the Development Potential Index of Creative Economy (DPIEC) which has been applied to all Brazilian states' capitals. In addition to this analysis more focused on the capital, the article also provides an overview of the state's creative economy and its concentration on the capital. The results, on the one hand, reveal the importance of creative activities in the economy of the city of Rio de Janeiro, which can be mobilized as engines of development, but, on the other hand, identify bottlenecks to be overcome in crucial factors for strengthening creative economy, especially those related to education, the attractiveness of the city of Rio de Janeiro and policies to support culture

Keywords: Creative economy. Development. Rio de Janeiro. Development Potential Index of Creative Economy.
D) João Luiz de Figueiredo ${ }^{a}$ (D) Diego Santos Vieira de Jesus ${ }^{\text {a }}$

${ }^{a}$ Escola Superior de Propaganda e Marketing (ESPM-Rio), Rio de Janeiro, RJ, Brasil

DOI: $10.12957 /$ geouerj.2020.47276

Correpondência: joao_luiz@globo.com

Recebido em: 16 set. 2019 Revisado em: 27 out. 2019 Aceito em: 13 dez.2019 


\section{INTRODUÇÃO}

A economia criativa tem sido amplamente debatida nos ambientes acadêmicos e das políticas públicas em função da crescente relevância dos setores criativos na economia e da sua relação com o desenvolvimento. Em outras palavras, ao tratarmos da importância da economia criativa na atual fase do capitalismo reconhecemos, por um lado, a importância dos seus setores produtivos na geração de emprego e renda, na contribuição com Produto Interno Bruto (PIB), no comércio internacional e em outros indicadores econômicos (HOWKINS, 2001; FLORIDA, 2002), ao mesmo tempo em que há, por outro lado, um rico debate sobre a relação da economia criativa com o desenvolvimento em sentido amplo, de maneira que se aponta para o potencial transversal da economia criativa que seria capaz de impactar a economia e a sociedade de modo geral, além dos seus setores produtivos. Nessa perspectiva, reconhecem-se, além dos efeitos diretos das atividades culturais e criativas, a existência de vários efeitos indiretos que agem, por exemplo, na construção de amenidades urbanas que acabam por favorecer a atração de investimentos de outros setores produtivos (MACHADO, SIMÕES e DINIZ, 2013), na ampliação da capacidade inovativa das organizações em um dado território por meio do fortalecimento de políticas culturais (CUNNINGHAM, 2013), na construção de competências territoriais em função da tendência das empresas e trabalhadores buscarem as economias de aglomeração (LAZZERETTI, BOIX e CAPONE, 2013), e até mesmo em uma nova mentalidade acerca das políticas públicas que podem se tornar mais criativas por influência ecossistema criativo local (LANDRY, 2008).

Na medida em que todos esses debates se aprofundaram, a necessidade de construção de dados e de indicadores apareceu como um importante entrave à identificação da importância da economia criativa e para a formulação de políticas públicas voltadas ao seu fortalecimento.

No Brasil, o primeiro esforço na construção de dados sobre a economia criativa foi realizado por Prestes Filho e Cavalcanti (2002) que identificava a força das indústrias culturais para o desenvolvimento do Rio de Janeiro, porém de forma mais estruturada e com perenidade no acompanhamento merece destaque o mapeamento da indústria criativa no Brasil feita pela Federação das Indústrias do Rio de Janeiro (FIRJAN), cuja primeira edição foi publicada em 2008 e a última em 2019 (FIRJAN, 2008; FIRJAN 2019). Na sequência, podemos afirmar que a segunda década do século XXI foi extremamente profícua em termos de avanços acadêmicos no entendimento da relevância da economia criativa para o desenvolvimento do Brasil e de suas Unidades da Federação, bem como na construção de indicadores capazes de estimar o seu tamanho e potencial de desenvolvimento, com destaques para trabalhos focados na realidade brasileira, como Barbalho, Calabre, Miguez e Rocha (2011); Leitão e Machado (2016); Valiati e Moller (2016); Jesus e Kamlot (2016); Figueiredo e Jesus (2017); dentre tantos outros.

Em consonância com tais esforços, temos dedicado especial atenção a dinâmica da economia criativa na cidade do Rio de Janeiro, bem como no recorte estadual, conforme publicações realizadas nos últimos anos 
(MEDEIROS JR, GRAND JR e FIGUEIREDO, 2011; FIGUEIREDO, 2017; FIGUEIREDO, JESUS, ROBAINA e COURI, 2019), as quais serão melhor debatidas nas próximas seções do presente artigo, o qual tem como objetivo principal identificar as oportunidades e os gargalos para o fortalecimento da economia criativa na cidade do Rio de Janeiro.

Para atingir o objetivo proposto, utilizaremos dados secundários da FIRJAN (2019) para analisar o panorama atual da economia criativa no estado do Rio de Janeiro e debateremos dados secundários de diversas bases estatísticas que serviram para a construção do Índice de Desenvolvimento Potencial da Economia Criativa (IDPEC) e posterior aplicação às capitais do Brasil (FIGUEIREDO, JESUS, ROBAINA e COURI, 2019). A estrutura do artigo possui três seções, além da introdução e das considerações finais. Na primeira, intitulada "Panorama atual da economia criativa no estado do Rio de Janeiro" apresentaremos a situação da economia criativa no estado, revelando a disparidade regional e o efeito da crise econômica nesta segunda década do século XXI; na segunda seção nomeada "O potencial do desenvolvimento da economia criativa na cidade do Rio de Janeiro" revelaremos como a capital do estado se comporta frente às outras capitais do Brasil quando estimamos a potencialidade da economia criativa se tornar um elemento do futuro desenvolvimento da cidade; na terceira, intitulada "Oportunidades e gargalos para o desenvolvimento da economia criativa na cidade do Rio de Janeiro", debatemos com maior profundidade os dados secundários mobilizados para a construção do IDPEC que apontam os gargalos à economia criativa na capital do estado fluminense.

Como já se pode perceber, o debate parte de uma análise estadual para depois focar mais detalhadamente na capital. É importante dizer que isso não implica a desconsideração das especificidades regionais do interior fluminense, mas acreditamos que a análise, que será apresentada a seguir, serve em boa parte para inspirar os demais municípios e/ou regiões fluminenses a pensarem políticas voltadas para o fortalecimento da economia criativa.

Panorama atual da economia criativa no estado do Rio de Janeiro

Segundo os dados compilados pela FIRJAN (2019), o PIB das empresas criativas do estado do Rio de Janeiro totaliza $\mathrm{R} \$ 24,8$ bilhões, equivalendo a 3,8\% de toda a riqueza produzida no estado; existem cerca de 25 mil empresas criativas no estado, as quais correspondem a 5,6\% do total; e 89 mil empregos formais são relacionados às atividades criativas, 2,2\% do total. Esses números demonstram a importância das atividades criativas na economia estadual, ainda mais se reconhecemos que nenhum estado brasileiro possui maior participação de empresas criativas no seu total de empresas do que o Rio de Janeiro e que apenas São Paulo supera o Rio na participação do PIB criativo no total de seu PIB e na participação do emprego criativo no total de empregos. O mesmo levantamento destaca ainda que o estado do Rio de Janeiro possui a maior média 
salarial da economia criativa, $\mathrm{R} \$ 10.667$, número bem superior à média nacional desse campo produtivo, $\mathrm{R} \$$ 6.801, e mais de três vezes superior ao salário médio fluminense, $\mathrm{R} \$$ 3.197.

Porém, ao analisarmos a distribuição da economia criativa pelo estado do Rio de Janeiro, percebemos uma importante desigualdade regional. Em um trabalho anterior apontamos que aproximadamente $77 \%$ dos empregos formais da economia criativa fluminense estavam concentrados na capital, que por sua vez apresentava forte dinâmica de crescimento dessas atividades na primeira década do século XXI, as quais geravam 10\% da massa salarial da cidade (MEDEIROS JR, GRAND JR e FIGUEIREDO, 2011). Em outro trabalho (FIGUEIREDO, 2017), mostramos como na primeira década do século XXI o crescimento do emprego na economia criativa se concentrou nas cidades do Rio de Janeiro e de Niterói, mas também com resultados positivos em Campos dos Goytacazes, Itaguaí, Volta Redonda, Petrópolis e Duque de Caxias.

Ao contrário da primeira década do século XXI, os anos 2010 são fortemente caracterizados por uma profunda crise econômica e política do país, que afetou seriamente a economia fluminense partir de 2015 . A economia criativa fluminense também sofreu com a recessão, especialmente as atividades criativas que são mais conectadas aos demais setores produtivos da economia, como a arquitetura, design e P\&D. Segundo a FIRJAN (2019), entre 2015 e 2017 os postos de trabalho na economia criativa reduziram-se em 12,1\%, sendo que arquitetura reduziu 35,5; design, 16,8\% e P\&D, 14,4\%. Por outro lado, as atividades criativas mais relacionadas à cultura e às mídias demonstraram maior resiliência aos contratempos macroeconômicos.

Em termos de distribuição dos empregos criativos pelo estado do Rio de Janeiro, houve uma pequena redução do peso da capital, mas a concentração ainda é muito marcante, $74 \%$ dos empregos criativos estão na cidade do Rio de Janeiro. Esse padrão é uma tendência global, uma vez que trabalhos da geografia econômica explicam que as empresas e os trabalhadores da economia criativa tendem a se aglomerar nas cidades que ocupam o topo da hierarquia urbana em função das forças de interdependência existentes no sistemas produtivos desverticalizados da economia criativa (SCOTT, 2008; LAZZERETTI, BOIX e CAPONE, 2013).

Apesar da crise econômica que marca os anos 2010 e da concentração da economia criativa na capital do estado do Rio de Janeiro, todos os municípios fluminenses possuem potencial para desenvolver seus setores criativos da economia e existem dois caminhos gerais para isso. O primeiro diz respeito à mobilização produtiva das especificidades culturais e históricas, de maneira que concordamos com Landry (2008) na ideia de que não existe lugar no mundo que não possua alguma característica histórica, social ou cultural que não possa ser mobilizada produtivamente em prol do seu desenvolvimento socioeconômico. O outro caminho é a conexão das atividades criativas com a base produtiva local, como forma de ampliar a competitividade e a capacidade inovativa das organizações e dos empreendedores, de modo a reconhecer a contribuição de atividades como design, publicidade, arquitetura e P\&D no desenvolvimento de novos produtos e serviços com maior valor agregado e com maior competitividade no mercado. Tal conexão se evidencia em Macaé, que 
possui $72,2 \%$ dos profissionais criativos trabalhando no segmento de P\&D e em Resende que $67,8 \%$ dos postos de trabalho criativo no setor de tecnologia. É importante sublinhar que as múltiplas competências criativas não servem apenas para as atividades culturais como muitos erradamente costumam entender, ao contrário disso, os profissionais da economia criativa possuem enorme potencial para trabalhar em diversos setores da atividade econômica e fortalecer nestes a capacidade da inovação. Ademais, como já lembrado por Cunningham (2013), mesmo as políticas culturais servem também para ampliar o potencial de inovação dos trabalhadores e das organizações em um dado território, em um processo definido pelo autor como "inovação escondida".

Se a conjuntura atual não é favorável, em função da crise econômica, podemos, por outro lado, questionar se as bases para o fortalecimento da economia criativa estão sólidas no Rio de Janeiro para o momento da retomada da economia. Tal questionamento é importante, pois acreditamos estarmos diante de uma nova fase do capitalismo em que será crescente a relevância das competências criativas na trajetória de desenvolvimento econômico e social, assim como no processo de reestruturação produtiva das cidades. Apesar da variedade de títulos, "capitalismo informacional” (CASTELLS, 1996), "capitalismo criativo" (FLORIDA, 2005), "capitalismo cognitivo" (BOUTANG, 2007), "capitalismo cultural-cognitivo" (SCOTT, 2008), reconhecese, em comum, que essa nova fase do capitalismo se caracteriza mais pela lógica da inovação em um regime de invenção do que pela lógica da reprodução em um regime de repetição outrora hegemônico, de modo que a cultura e a criatividade se configuram em recursos fundamentais de geração de valor econômico e de diferenciação em mundo cada vez mais globalizado.

Diante disso, propusemos a criação de um índice capaz de estimar o desenvolvimento potencial da economia criativa (IDPEC) nas cidades brasileiras (FIGUEIREDO, JESUS, ROBAINA e COURI, 2019), o qual será explicado com ênfase na cidade do Rio de Janeiro na próxima seção do artigo.

\section{O potencial do desenvolvimento da economia criativa na cidade do Rio de Janeiro}

O IDPEC, que construímos e aplicamos às capitais do Brasil (FIGUEIREDO, JESUS, ROBAINA e COURI, 2019), trata da mensuração do potencial do desenvolvimento da economia criativa, consistindo em um indicador composto a partir de dados secundários. Diante do desafio de quantificar o potencial da economia criativa e não apenas a sua situação atual, incluímos em nossa pesquisa uma variedade de dados que extrapola a análise das atividades produtivas da economia criativa em si, de modo que incorporamos variáveis reconhecidas como fundamentais para o fortalecimento da economia criativa.

Os procedimentos metodológicos para a construção do IDPEC consistiram em três etapas, sendo a primeira dedicada a revisão teórica de alguns índices já construídos e aplicados para a compreensão do 
dinamismo da economia criativa em diversos países. Na segunda etapa, selecionamos os indicadores para a análise da realidade brasileira, os quais foram agregados em três dimensões: talento; atratividade e conexões; ambiente cultural e empreendedorismo criativo. Na terceira etapa dos procedimentos metodológicos, após o levantamento de todos os dados, recorremos à normalização dos dados para podermos compará-los e na sequência calculamos o IDPEC a partir de duas técnicas, uma que atribuiu pesos iguais às três dimensões e outra que estabelece pesos diferentes através da técnica de pesos endógenos proposta por Bowen; Moesen e Sleuwaegen (2008).

Embora no Brasil a construção para índices aplicados ao campo da economia criativa ainda seja rara, existem experiências importantes em outros países em função da crescente importância que essas atividades têm desempenhado no conjunto das economias nacionais, estaduais ou locais (CORREIA E COSTA, 2014). Segundo Castro-Higueiras e De Aguilera Moyano (2016), os índices permitem uma estimativa de um fenômeno complexo e multidimensional que não é possível de ser medido diretamente, constituindo-se em uma poderosa ferramenta quantitativa para a definição de políticas públicas apesar das imprecisões inerentes a qualquer sistema que pretenda capturar a realidade.

Nas figuras abaixo, apresentamos os resultados que foram encontrados em nossa pesquisa e que já permitem visualizar a situação da cidade do Rio de Janeiro em comparação com todas as outras capitais do Brasil. As figuras 1, 2 e 3 apresentam os resultados de cada dimensão analisada na construção do IDPEC e o seu resultado final.

Figura 1. Ranking das capitais brasileiras e do Distrito federal na dimensão 1 (Talento) do IDPEC. Fonte: Retirado de Figueiredo, Jesus, Robaina e Couri (2019)

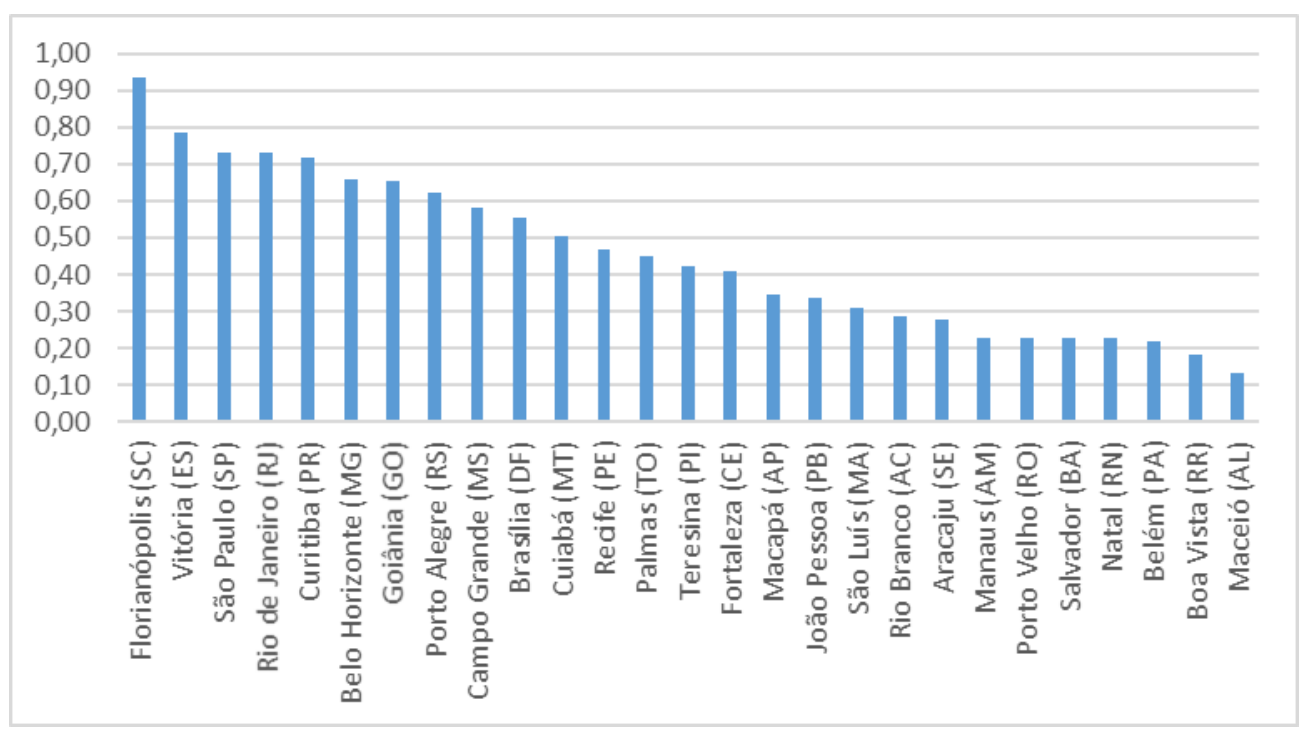


Figura 2. Ranking das capitais brasileiras e do Distrito federal na dimensão 1 (Atratividade e conexões) do IDPEC. Fonte: Retirado de Figueiredo, Jesus, Robaina e Couri (2019)

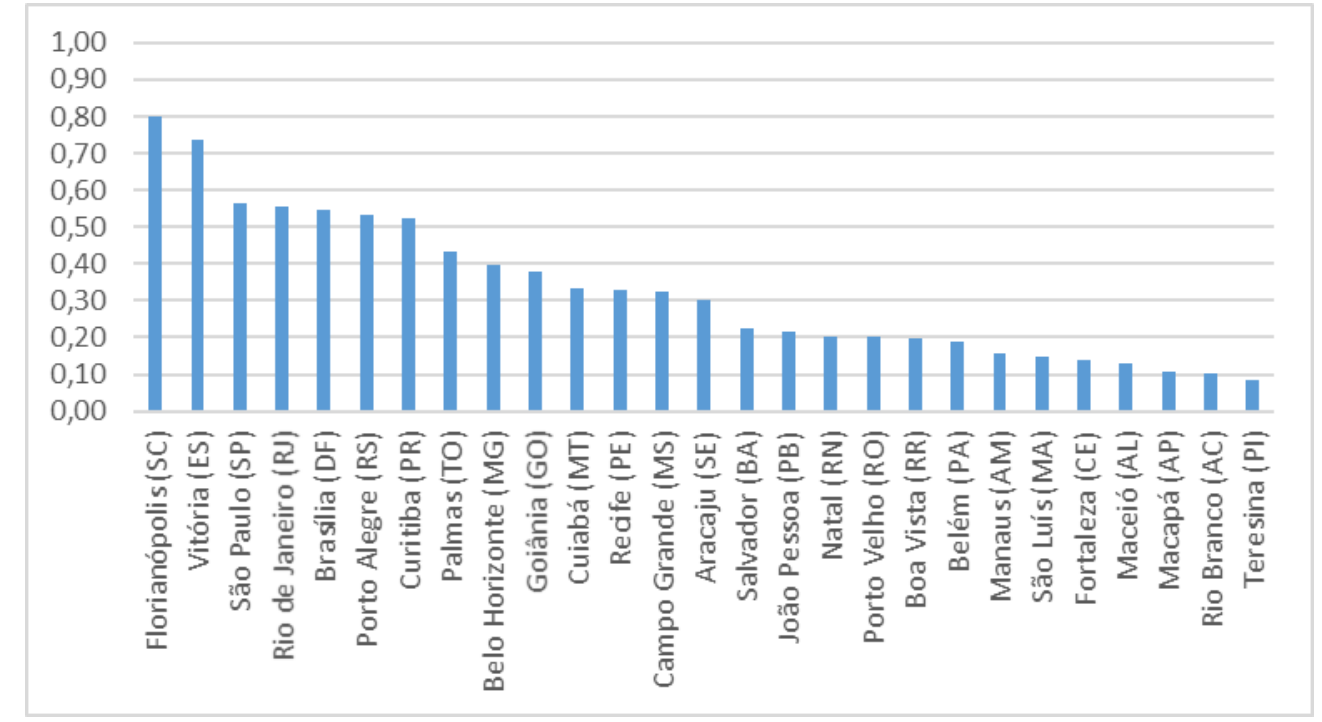

Figura 3. Ranking das capitais brasileiras e do Distrito federal na dimensão 1 (Ambiente cultural e empreendedorismo criativo) do IDPEC. Fonte: Retirado de Figueiredo, Jesus, Robaina e Couri (2019)

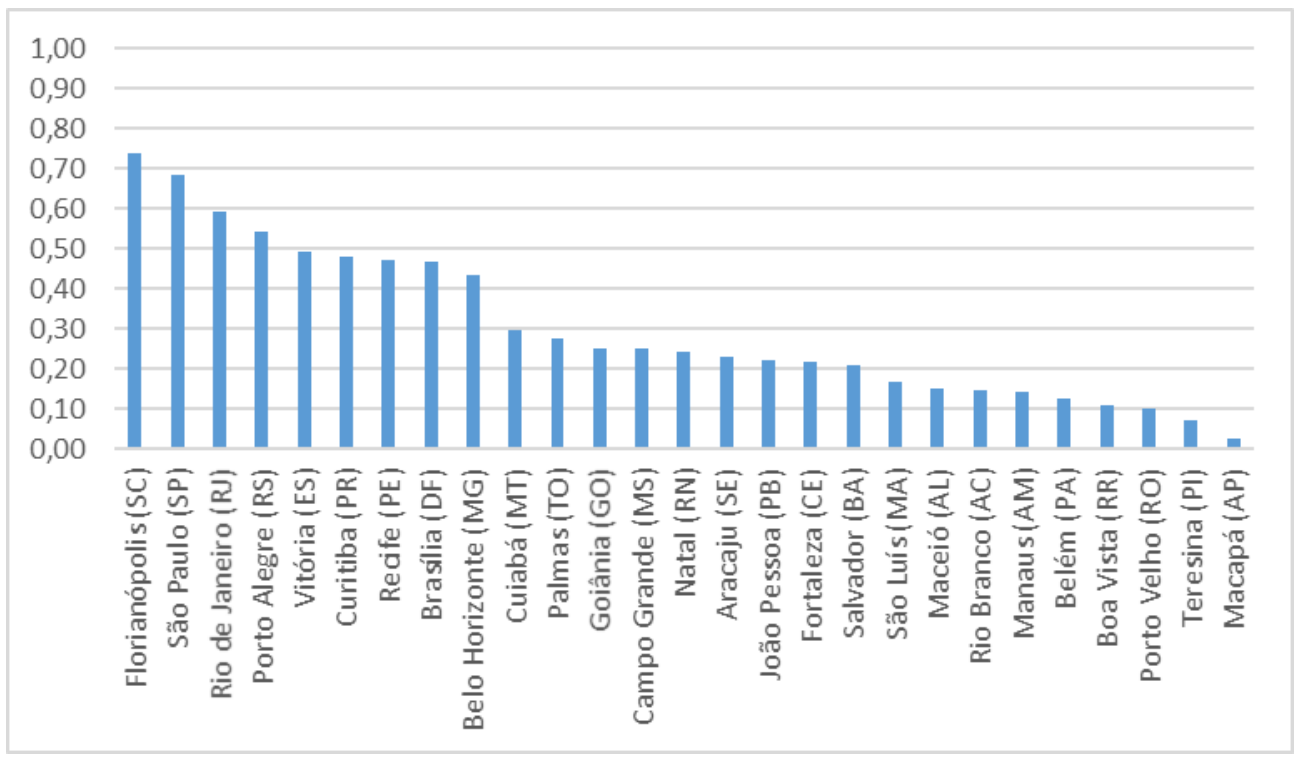

Ao analisarmos os três gráficos, percebemos uma forte desigualdade nacional no desenvolvimento do potencial da economia criativa, uma vez que os capitais dos estados no Norte e do Nordeste possuem resultados bem abaixo dos encontrados nas capitais dos estados do Sul e do Sudeste, sendo Recife uma exceção. Portanto, se é correto o diagnóstico de que as atividades criativas desempenharão papel crescente na economia global, isso tenderá a ampliar a desigualdade regional brasileira. 
O caso do Rio de Janeiro revela um quadro que merece atenção dos gestores das políticas públicas, pois, se por um lado, reconhecemos que a cidade tem um conjunto de atividades culturais e criativas dinâmico, por outro, identificamos problemas que podem limitar esse desenvolvimento da economia criativa na cidade. A cidade não liderou não possui o melhor desempenho em nenhuma das três dimensões analisadas com resultados abaixo da média nacional em alguns indicadores que medem o desenvolvimento de pessoas para trabalhar nos setores culturais e criativos (dimensão 1 do IDPEC - talento) e que avaliam a atratividade da cidade para pessoas do Brasil e do Mundo (dimensão 2 do IDPEC - atratividade e conexões). O melhor desempenho da cidade é justamente quando se identifica o dinamismo do setor produtivo na cidade apesar de também ficar aquém da expectativa (dimensão 3 do IDPEC - ambiente cultural e empreendedorismo criativo).

Na figura 4 que se segue, verifica-se a situação final do IDPEC referente ao ano de 2017, em que a cidade do Rio de Janeiro se apresenta como a quarta capital brasileira com maior potencial de desenvolvimento da economia criativa.

Figura 4. Ranking das capitais brasileiras e do Distrito federal no IDPEC (peso endógeno). Fonte: Retirado de Figueiredo, Jesus, Robaina e Couri (2019)

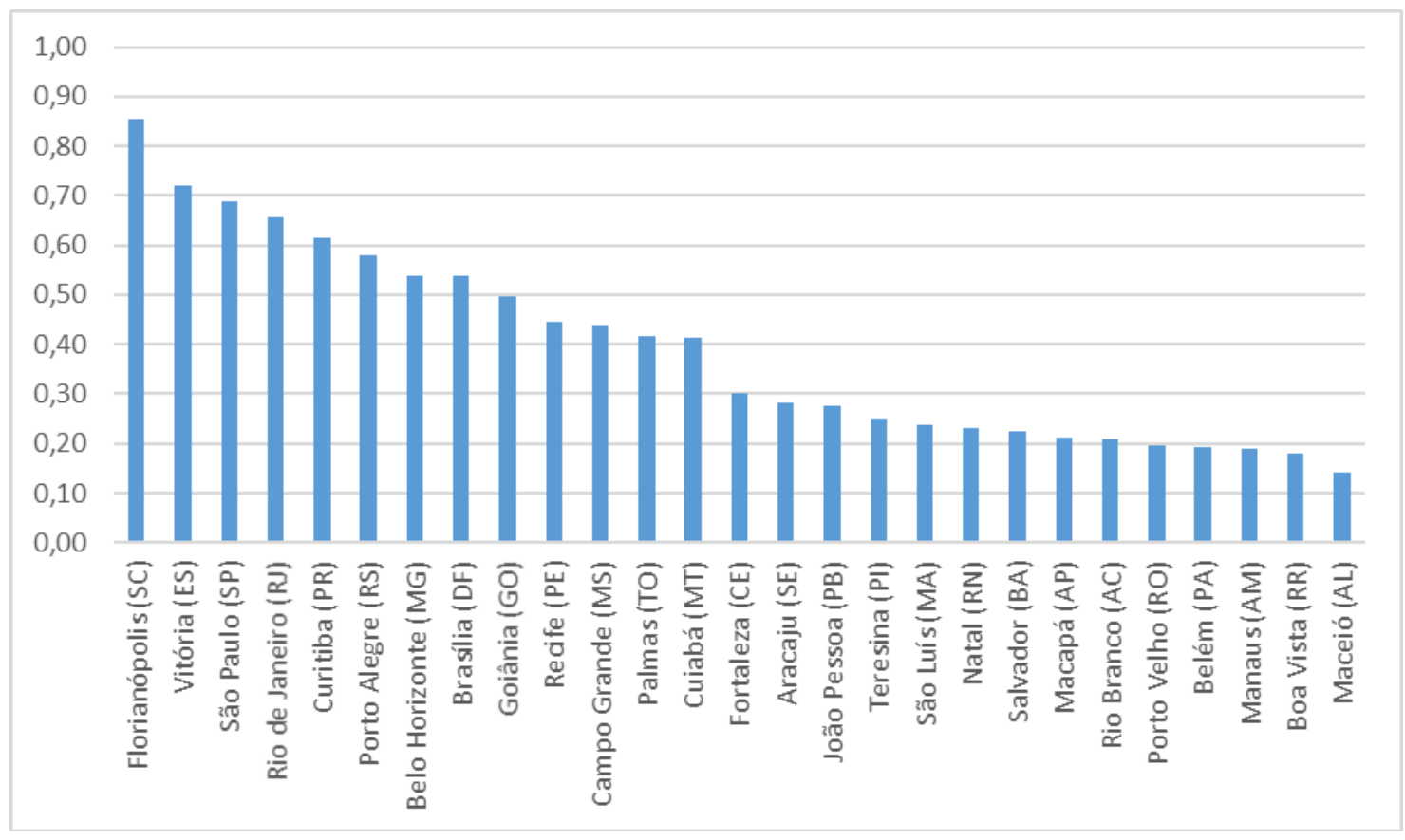

Em Figueiredo, Jesus, Robaina e Couri (2019) o nosso objetivo não era explorar individualmente as razões para o resultado encontrado em cada capital, no entanto consideramos este um exercício muito 
importante de ser feito, de maneira que o faremos agora para a cidade do Rio de Janeiro ao analisarmos as oportunidades e os gargalos para o desenvolvimento da economia criativa na cidade do Rio de Janeiro.

\section{Oportunidades e gargalos para o desenvolvimento da economia criativa na cidade do rio de janeiro}

O estado do Rio de Janeiro, assim como a sua capital, sempre desempenhou papel importante no conjunto da economia criativa brasileira, sendo pioneiro na proposição de políticas para o seu fortalecimento. Todavia, os sinais da crise econômica e política que o país atravessa desde 2015 se manifestaram de maneira mais intensa nessa unidade da federação, de modo que as atividades culturais e criativas também sofreram. O impacto negativo não deve ser percebido apenas no curto prazo, em função de variações de emprego e de renda do setor, mas deve-se pensar nos efeitos negativos de longo prazo que podem ser gerados pela fuga de empresas e de trabalhadores e, principalmente, pela visão de lideranças políticas que não reconhecem a importância das atividades culturais e criativas em termos econômicos e simbólicos. Nesta seção do artigo identificaremos os gargalos para o fortalecimento da economia criativa na cidade do Rio de Janeiro a partir dos dados secundários que levantamos para a construção do IDPEC em 2017. Entendemos como gargalos os indicadores que freiam o desenvolvimento da economia criativa, especialmente alguns que possuem efeitos de longo prazo como a qualidade da educação básica. Para que possamos fazer essa explicação, apresentamos no quadro 1 abaixo todos os indicadores que utilizamos para construirmos o IDPEC.

Quadro 1. Dimensões e variáveis do IDPEC. Fonte: Retirado de Figueiredo, Jesus, Robaina e Couri (2019)

\begin{tabular}{|c|c|c|c|}
\hline Dimensão & Variáveis & Descrição & Fonte \\
\hline \multirow{3}{*}{ D1 - Talento } & T1 - Capital humano & $\begin{array}{c}\text { Proporção de pessoas com } \\
\text { ensino superior }\end{array}$ & Censo IBGE 2010 \\
\hline & T2 - Emprego criativo & Proporção de emprego criativo & RAIS - Ministério do Trabalho \\
\hline & T3 - Educação básica & $\begin{array}{l}\text { Média da performance dos } \\
\text { estudantes na educação básica }\end{array}$ & $\begin{array}{c}\text { INEP - Instituto Nacional de } \\
\text { Estudos e Pesquisas } \\
\text { Educacionais }\end{array}$ \\
\hline \multirow{5}{*}{$\begin{array}{l}\text { D2 - Atratividade e } \\
\text { conexões }\end{array}$} & A1 - Atratividade nacional & $\begin{array}{c}\text { Proporção de não-locais entre os } \\
\text { residentes }\end{array}$ & Censo IBGE 2010 \\
\hline & A2 - Atratividade internacional & $\begin{array}{c}\text { Proporção de não-nacionais } \\
\text { entre os residentes }\end{array}$ & Censo IBGE 2010 \\
\hline & $\begin{array}{c}\text { A3 - Índice de Desenvolvimento } \\
\text { Humano (IDH) }\end{array}$ & $\begin{array}{c}\text { Índice Municipal de } \\
\text { Desenvolvimento Humano }\end{array}$ & Censo IBGE 2010 \\
\hline & A4 - Mobilidade urbana & $\begin{array}{c}\text { Proporção de estradas e ruas } \\
\text { urbanizadas }\end{array}$ & Censo IBGE 2010 \\
\hline & A5 - Movimento aeroportuário & $\begin{array}{c}\text { Número de passageiros } \\
\text { aeroportuários per capita }\end{array}$ & Ministério do Transporte \\
\hline \multirow{5}{*}{$\begin{array}{c}\text { D3 - Ambiente cultural e } \\
\text { empreendedorismo } \\
\text { criativo }\end{array}$} & C1 - Indústrias criativas & Proporção de empresas criativas & RAIS - Ministério do Trabalho \\
\hline & C2 - Salário criativo & Proporção de salário criativo & RAIS - Ministério do Trabalho \\
\hline & C3 - Patentes & Número de patentes per capita & $\begin{array}{l}\text { INPI - Instituto Nacional de } \\
\text { Propriedade Industria }\end{array}$ \\
\hline & C4 - Oferta cultural & Número de museus per capita & $\begin{array}{c}\text { IBRAM - Instituto Brasileiro } \\
\text { de Museus }\end{array}$ \\
\hline & $\begin{array}{c}\text { C5 - Incentivo público para a } \\
\text { cultura }\end{array}$ & $\begin{array}{c}\text { Despesa pública direta em } \\
\text { cultura per capita }\end{array}$ & FINBRA - Finanças brasileiras \\
\hline
\end{tabular}


Na Dimensão Talento, a cidade do Rio de Janeiro se destaca dentre as demais capitais do Brasil pela importância que o emprego criativo tem em sua economia, de modo que essa característica pode determinar o crescimento das atividades culturais e criativas nos próximos anos se considerarmos a tendência que as atividades econômicas têm de retroalimentarem suas próprias trajetórias, segundo a perspectiva evolucionista de Arthur (1990). Por outro, lado os outros indicadores desta dimensão, que tratam da educação básica e da formação de capital humano - que se refere a pessoas com ensino superior - além de possuírem resultados ruins comparados aos das demais capitais do Brasil, são afetados por uma grave crise de naturezas política, econômica e técnica na cidade e no Estado do Rio de Janeiro. Em termos políticos, a corrupção limita os recursos para uma educação criativa, cuja promoção também é comprometida pela instabilidade política e pelos choques de interesse entre formuladores de decisão. Tais choques comprometem a continuidade de políticas dedicadas a uma educação que estimule o desenvolvimento de habilidades criativas, a aquisição de competências empreendedoras e a internalização de noções de cidadania. Cumpre destacar também que o acesso a escolas e universidades torna-se mais difícil com o acirramento do crime e da violência. Em termos econômicos, o déficit nas contas públicas limitou os recursos dos governos destinados ao investimento em setores estratégicos, como a educação. A recessão econômica, aliada à queda na arrecadação no Estado do Rio de Janeiro, levou à maior pauperização da população, reduzindo-se também a oportunidade para empregos criativos. Muitos estudantes não puderam completar sua formação educacional porque precisaram entrar no mercado de trabalho cada vez mais cedo, em posições subalternas. Quanto à natureza técnica da crise, a infraestrutura educacional não lida efetivamente com a interdisciplinaridade e a transversalidade do conhecimento, nem traz formas inovadoras de promovê-las nas escolas ou de desenvolver a transdisciplinaridade entre as áreas cultural, tecnológica e empreendedora desde os primeiros estágios do processo educacional. Ademais, em grande parte das instituições privadas de educação básica e secundária no Rio de Janeiro, o foco ainda está na preparação dos estudantes para a entrada nas universidades, com uma preocupação escassa em relação ao estímulo às competências artísticas e criativas, bem como a uma visão mais crítica sobre as questões sociais mais densas nas sociedades carioca, fluminense e brasileira. Nas instituições públicas de ensino superior e também em algumas privadas, os bloqueios e os contingenciamentos de recursos ocorridos em anos recentes e acentuados em 2019, inclusive em instituições localizadas no Rio de Janeiro, reduziram verbas disponíveis para a produção científica com impacto significativo sobre a gestão pública e o sistema produtivo (JESUS, KAMLOT, DUBEUX, 2019).

Em relação à Dimensão Atratividade e Conexões, é preciso, primeiramente, analisar as políticas governamentais em âmbito estadual. Os arranjos metropolitanos - particularmente as regiões metropolitanas - receberam maior atenção que cidades médias e pequenas, não somente por conta da abrangência territorial, mas pela concentração demográfica, tendo em vista que essas regiões abrigam a maior parte da população e têm fundamental papel na composição do PIB. Os desafios políticos na gestão de cidades médias e pequenas 
- em particular daquelas que integram regiões metropolitanas ou conurbações urbanas - não se limitam estritamente a administrar o desafio demográfico privilegiando políticas de habitação e mobilidade, mas abarcam também lidar com temas como violência urbana, precária oferta de serviços de educação e saúde, problemas de saneamento básico, desemprego e concentração de renda (ARRAIS, 2008). No caso do Estado do Rio de Janeiro, uma série de fatores coloca barreiras à atratividade e à formação de conexões, como a estratificação do espaço urbano - o que dificulta a fixação de não-locais entre os residentes e afeta diretamente as variáveis "Atratividade nacional" e "Atratividade internacional" em regiões da capital e da região metropolitana - e o foco excessivo dos governos municipais em seus interesses específicos em âmbito local às custas da comunidade regional mais ampla, em grande parte explicada pelas disputas interpartidárias entre diferentes níveis de governo e com lideranças de outras cidades e pela manutenção de esquemas de corrupção. Como aponta Abreu (1987), embora o crescimento urbano desordenado tenha criado escala de demanda para a diversificação e ampliação da oferta de bens e serviços, o estado teve suas infraestruturas urbanas física - como moradias, saneamento e transporte público - e social - educação, saúde e lazer pressionadas ao limite, o que agravou problemas como degradação ambiental, questões de mobilidade urbana, déficit habitacional e violência, o que interfere diretamente nas variáveis "IDH" e "Mobilidade urbana" desta dimensão ao observarmos especificamente o caso da cidade do Rio de Janeiro. Os déficits sociais são supridos de maneira precária, de forma a se conduzir a crescimento das favelas, loteamentos irregulares, população de rua e avanço do tráfico de drogas, que teve especialmente nos morros da capital uma localização estratégica de defesa e logística (LOUREIRO, 2006; PRETECEILLE; VALLADARES, 2000).

Com relação às variáveis que compõem a Dimensão Ambiente Cultural e Empreendedorismo Criativo, a força das atividades culturais e criativas na cidade se manifesta mais uma vez quando se verifica que a cidade possui o maior salário médio dessas atividades no Brasil e tem uma expressiva quantidade de empresas atuantes no setor. Porém, existem ameaças à médio e longo prazo pelo fato de que as ações e as instituições voltadas para a esfera cultural e artística no Rio de Janeiro sofreram impactos negativos com as descontinuidades de suas políticas, as restrições financeiras, a deficiência de quadros técnicos e as relações clientelistas, que resultaram em maior dependência de seus agentes em relação aos favores de gestores governamentais e seus intermediários (JESUS; KAMLOT, 2016). Dentre as que mais sofrem os impactos desses fatores, cabe destacar "Oferta cultural" e "Incentivo público à cultura". Já "Indústrias criativas" e "Salário criativo" são impactadas pela falta de novas linhas de crédito para fomentar os empreendimentos criativos, bem como de uma educação para competências criativas e de uma infraestrutura eficiente que garanta a criação/produção, difusão/circulação e fruição/consumo de bens e serviços criativos dentro e fora do Rio de Janeiro. Cabe também sinalizar como obstáculo ao desenvolvimento de setores criativos a ausência ou escassez de marcos regulatórios tributários, trabalhistas, previdenciários e civis que permitam o desenvolvimento das dinâmicas econômicas dos setores culturais e criativos cariocas e fluminenses. Como 
sinaliza Leitão (2015), a descontinuidade das políticas públicas para a economia criativa impacta negativamente o campo cultural, fragilizando ainda mais o grande contingente de artistas, profissionais, pequenos empreendedores e gestores dos setores culturais e criativos, formais e informais. No contexto de dificuldades burocráticas, a variável "Patentes" é influenciada negativamente por conta da demora na concessão dessas por parte do Instituto Nacional da Propriedade Intelectual (INPI), que pode demorar mais de dez anos para conferir uma patente a um produto, trazendo custos enormes para as empresas (SOARES, 2018).

\section{CONSIDERAÇÕES FINAIS}

Pode-se dizer que, embora o Rio de Janeiro reúna uma série de características que permitam o desenvolvimento ainda maior da economia criativa na cidade, existem obstáculos de ordens política, econômica, sociocultural e técnica que não só impedem esse desenvolvimento, mas acabam levando a retrocessos em inúmeros pontos abarcados pelas variáveis do IDPEC. As articulações críticas da produção, comércio e relações financeiras foram enfraquecidas com o agravamento da violência urbana, a crise econômica e fiscal do Estado e as denúncias de corrupção envolvendo autoridades municipais e estaduais, bem como a falta de estímulos à diversidade da produção cultural e a limitação de recursos para a inovação. No âmbito da segurança pública, o Estado foi alvo de uma intervenção federal ao longo de grande parte do ano de 2018, que visou a conter o comprometimento da ordem pública em face do agravamento da violência a partir da segunda metade de 2017. A situação remetia ao acirramento das crises política e econômicofinanceira no Rio de Janeiro, e a intervenção buscaria um sistema mais robusto de segurança social para uma coordenação mais estreita entre as forças de segurança e a ampliação da capacidade operacional e da maior integração da inteligência (ROSSI, 2018). Entretanto, na cidade do Rio de Janeiro, houve aumentos expressivos da letalidade violenta no período nas regiões da Rocinha, Ipanema, Leblon, Gávea, Jardim Botânico, Lagoa, São Conrado e Vidigal, em grande parte explicada pela guerra entre policiais e traficantes e entre grupos criminosos rivais nas favelas da Zona Sul da cidade.

A recessão econômica do Estado do Rio de Janeiro - concomitante à retração nas atividades da indústria do petróleo e à queda da arrecadação - também conduziu à pauperização crescente da população. Como colocam Callegari \& Wermuth (2011), a população economicamente hipossuficiente, quando abandonada pelo Estado nas dimensões social e econômica, pode buscar, por meio da delinquência, a satisfação das necessidades básicas. O quadro de crise foi agravado com a corrupção disseminada pelo aparato político, evidente com a prisão dos ex-governadores Sérgio Cabral Filho em 2016 no contexto da Operação Lava Jato e Luiz Fernando Pezão em 2018, acusado de receber quase R\$ 40 milhões em propinas de contratos do governo estadual. Além deles, foram presos ex-secretários e conselheiros do Tribunal de Contas. A situação conduziu 
não apenas a problemas como a escassez de verbas para o pagamento de salários dos servidores estaduais, mas ao gradual colapso de programas do governo do Estado, como as Unidades de Pronto-Atendimento (UPAs) e as Unidades de Polícia Pacificadora (UPPs) ao longo de 2017 (O ESTADO DE S. PAULO, 2017).

Grande parte dos principais setores criativos formais - caracterizados pelo desenvolvimento de atividades produtivas que têm como processo principal um ato criativo gerador de um produto e a dimensão simbólica é determinante do seu valor - concentra-se primordialmente na região metropolitana do Rio de Janeiro, particularmente nas Zonas Sul e Central da capital e no bairro da Barra da Tijuca. Quase $80 \%$ dos postos relacionados ao trabalho na economia criativa no estado se concentram na cidade do Rio de Janeiro, os quais correspondiam a pouco mais que $10 \%$ dos empregos gerados no fim da década de 2000 . No que diz respeito à diversidade das manifestações culturais, basta verificar o exemplo da própria capital a fim de se identificar como tal diversidade é tolhida. As deficiências na gestão e o escasso conhecimento técnico nos órgãos fiscalizadores conduzem à decadência física e simbólica do Patrimônio Cultural na cidade, o que ocorre concomitantemente às pressões exercidas por grupos particulares e à expansão urbana desordenada, muitas vezes para o uso comercial do espaço (JESUS, 2017).

A violência disseminada na esfera pública dificulta o acesso a uma série de equipamentos de lazer e cultura no estado do Rio de Janeiro, como as lonas e arenas culturais nas Zonas Norte e Oeste da capital. Grandes eventos culturais como o Rock In Rio em 2017 foram marcados pela dinâmica de guerras entre traficantes e a intervenção das Forças Armadas na favela da Rocinha durante o evento, cujos impactos refletiram-se na percepção de cariocas e turistas sobre a realização do festival (PREFEITURA DO RIO DE JANEIRO, 2017). A crise reduziu a quantidade de verbas a serem utilizadas na manutenção de equipamentos culturais que promovem as singularidades das regiões cariocas e no pagamento de funcionários desses equipamentos. No âmbito de eventos culturais, o ajuste fiscal promovido pelo prefeito Marcelo Crivella em 2017 atingiu as finanças de alguns dos principais eventos culturais da cidade, como os desfiles das escolas de samba e a Parada do Orgulho LGBTI-Rio. Crivella foi acusado de deixar que suas conviç̧ões religiosas interferissem nas decisões administrativas (MARTíN, 2017).

Em relação especificamente à inovação, a crise orçamentária e as denúncias de corrupção envolvendo agentes de inovação no setor político dificultaram a execução do papel dos governos como incentivadores e financiadores de empresas baseadas em novas tecnologias e pesquisas científicas, o que prejudica a cooperação governamental com o setor privado e as universidades. As indústrias e as empresas em geral investiram mais em inovação durante a crise, mas algumas das mais importantes estavam altamente endividadas ou envolvidas em sistemas de corrupção com entes governamentais, o que limitava os recursos para inovação. Além da intensificação dessas limitações, as universidades - públicas, principalmente - no Rio de Janeiro sofreram pesadamente com as limitações de verbas para a ciência e tecnologia, o que inviabilizou 
estudos, desmantelou grupos de pesquisa e conduziu a uma "fuga de cérebros" para fora do Rio de Janeiro e do Brasil (JESUS, 2019).

Grandes investimentos públicos e privados são tipicamente feitos em instalações culturais visando a ampliar a atratividade dos espaços para consumidores e trabalhadores qualificados (SCOTT, 2019). Esse tipo de intervenção ocorreu de forma irregular principalmente na cidade do Rio de Janeiro, em particular no contexto de preparação para os Jogos Olímpicos de 2016. O atual contexto de crise político-econômica coincide com o estancamento de investimentos públicos e privados após a realização dos Jogos Olímpicos de 2016, a queda da arrecadação por conta da recessão e a crise motivada pela excessiva dependência criada em relação à indústria do petróleo. No contexto pós-olímpico, é visível também a crise do setor imobiliário, com grande sobre-oferta de imóveis residenciais e comerciais, bem como no setor hoteleiro. Áreas revitalizadas como a região portuária da cidade poderiam ser locais em que as indústrias da cultura e do entretenimento fossem mais exploradas. Para tanto, a eliminação dos obstáculos ao empreendedorismo - em especial da burocracia, da morosidade na concessão de alvarás e da simplificação das condições para regularização de atividades econômicas criativas - seria fundamental (RAPS, 2016). Num contexto mais amplo, a tendência ao "empreendedorismo urbano" veio se consolidando como o modelo hegemônico de planejamento da escala local no contexto de um "localismo hipercompetitivo" em relação a práticas mais autônomas de desenvolvimento local e de aprofundamento da democracia participativa no planejamento urbano (MAGALHÃES, 2008).

Em face dos pontos apresentados, a fim de se permitir o amplo desenvolvimento do potencial da economia criativa no Rio de Janeiro, seria necessário o estímulo ao engajamento de grupos organizados da sociedade civil na formulação de políticas públicas e no acompanhamento das ações políticas e dos gastos das autoridades municipais, estaduais e federais, visando à conquista de maior transparência pública. A maior articulação entre as políticas de defesa nacional e de segurança pública mostra-se fundamental, em particular no que diz respeito à ampliação do monitoramento de fronteiras do país e do Estado do Rio de Janeiro visando a conter os tráficos de drogas e armas e a combater o roubo de cargas.

Mostram-se também necessárias ações que alimentem a percepção de coesão social na cidade e no Estado do Rio de Janeiro. Dentre elas, cabe citar o fortalecimento e a aceleração da discussão política acerca de projetos federais, estaduais e municipais que gerem renda e emprego para populações de menor renda e abaixo da linha da miséria, particularmente em setores ligados às vocações da cidade e dos demais municípios do Estado. Além disso, seria essencial o engajamento das autoridades públicas com o setor empresarial e o terceiro setor na capacitação de cidadãos para a inserção de tais pessoas em setores produtivos relacionados às vocações urbanas, com o aproveitamento de saberes e conhecimentos locais na geração de renda e emprego. 
Em termos do estímulo à coesão social, seria importante ampliar a cooperação institucional entre os diferentes níveis de governo, a iniciativa privada e setores organizados da sociedade civil na realização de eventos culturais e estimular a diversidade de manifestações artísticas e criativas na realização desses eventos, que permitam a criação e a consolidação de conexões entre as pessoas e a cidade e explorem seu potencial para o desenvolvimento e o exercício das liberdades individuais. Tal medida poderia vir acompanhada do incentivo à atividade das instituições responsáveis pela inserção internacional da cidade e do Estado do Rio de Janeiro a fim de se ampliarem as possibilidades de apresentação internacional desses locais a investidores e turistas, sinalizando ações tomadas visando à melhoria das condições político-econômicas e de segurança pública.

Por fim, destacamos que o índice construído permitirá ao longo dos anos acompanhar como as cidades estão potencializando o seu desenvolvimento pela perspectiva da economia criativa. Além disso, se os dados gerados permitiram traçar uma comparação entre as capitais do Brasil, entendemos que o próximo passo é a sua aplicação no estado do Rio de Janeiro para que possamos identificar os municípios fluminenses que possuem maior potencial de se desenvolverem por meio da economia criativa.

\section{REFERÊNCIAS}

ABREU, Maurício de. A evolução urbana do Rio de Janeiro. 3.ed. Rio de Janeiro: IPLANRIO/ZAHAR, 1987.

ARRAIS, Tadeu Alencar. A cidade e a região/a cidade-região: reconhecer processos, construir políticas. Cadernos Metrópole, n.20, p.81-91, 2008.

ARTHUR, Brian. Positive feedbacks in the economy. Scientific American, vol. 262(2), p. 92-99, 1990.

BARBALHO, Alexandre; CALABRE, Lia; MIGUEZ, Paulo; ROCHA, Renata (orgs.). Cultura e desenvolvimento: perspectivas políticas e econômicas. Salvador: EDUFBA, 2011.

BOUTANG, Yann Moulier. Le capitalisme cognitif: la nouvelle grand transformation. Paris: Éditions Amsterdam, 2007.

BOWEN, Harry P.; MOESEN, Wim; SLEUWAEGEN, Leo. A Composite Index of the Creative Economy. Review of Business and Economics, n.4, p.375-397, 2008.

CALLEGARI, André Luís; WERMUTH, Maiquel Angelo. Medo, direito penal e controle social. Revista da Faculdade de Direito - UFU, v. 39, n. 1, p. 133-168, 2011.

CASTELLS, Manuel. The rise of the network society (The information age: economy, society and culture, volume 1). Malden: Blackwell, 1996.

CUNNINGHAM, Stuart. Hidden innovation: policy, industry and the creative sector. Brisbane: University of Queensland Press, 2013.

FIGUEIREDO, João Luiz de. A dimensão econômica da cultura. In: MARAFON, Glaúcio e ROCHA, Geiza (orgs.). Caderno de cultura do estado do Rio de Janeiro. Rio de Janeiro: EdUERJ, 2017. p. 12-31. Disponível em: https://www.eduerj.com/eng/?product=cadernode-cultura-do-estado-do-rio-de-janeiro Acesso em: 14 out. 2019.

FIGUEIREDO, João Luiz de e JESUS, Diego Santos Vieira de (orgs.). Cidades criativas: aspectos setoriais e territoriais. Rio de Janeiro: EPapers, 2017.

FIRJAN. Federação das Indústrias do estado do Rio de Janeiro. A Cadeia da Indústria Criativa no Brasil. Rio de Janeiro: FIRJAN, 2008. 
FIRJAN. Federação das Indústrias do Estado do Rio de Janeiro. Mapeamento da indústria criativa no Brasil. Rio de Janeiro: FIRJAN, 2019. Disponível em: https://www.firjan.com.br/EconomiaCriativa/downloads/MapeamentolndustriaCriativa.pdf Acesso em 14 out. 2019.

FLORIDA, Richard. The rise of the creative class: and how it's transforming work, leisure, community, \& everyday life. Nova York: Basic Books, 2002.

FLORIDA, Richard. Cities and the creative class. New York: Routledge, 2005.

HOWKINS, John. The creative economy: how people are making money from ideas. Londres: Penguin Press, 2001.

JESUS, Diego Santos Vieira de. Saudade de mim: patrimônio cultural e economia criativa no Rio de Janeiro. In: FIGUEIREDO, João Luiz de; JESUS, Diego Santos Vieira de (Org.). Cidades criativas: aspectos setoriais e territoriais. 1ed. Rio de Janeiro: E-papers, 2017, v. 1, p. 157-177.

JESUS, Diego Santos Vieira de. Cidade próxima, região distante: os obstáculos a uma cidade-região no Estado do Rio de Janeiro. Grifos, v. 28, n. 46, p.115-135, 2019.

JESUS, Diego Santos Vieira de; KAMLOT, Daniel. Economia criativa e políticas públicas. Curitiba: Prismas, 2016.

JESUS, Diego Santos Vieira de; KAMLOT, Daniel; DUBEUX, Veranise Jacubowski Correia. The decline of creative education in the city of Rio de Janeiro: main causes and consequences. Creative Education, v. 10, p. 1670-1684, 2019.

LANDRY, Charles. The creative city: a toolkit for urban innovators. Londres: Earthscan, 2008.

LAZZERETTI, L.; BOIX, R.; CAPONE, F. Why do creative industries cluster? In: LAZZERETTI, L. (Ed.) Creative Industries and Innovation in Europe: concepts, measures and comparative case studies. Nova York: Routledge, 2013. p. 45-64.

LEITÃO, Cláudia. Economia criativa e desenvolvimento. Revista Será?, 24 jul. 2015. Disponível em: <http://revistasera.info/economia-criativa-e-desenvolvimento-claudia-leitao/>. Acesso em: 18 dez. 2015.

LEITÃO, Claudia e MACHADO, Ana Flávia (orgs.). Por um Brasil criativo: significados, desafios e perspectivas da economia criativa brasileira. Belo Horizonte: Código Editora, 2016.

LOUREIRO, Ana Cláudia Nonato da Silva. Rio de Janeiro: uma análise da perda recente de centralidade. Dissertação de Mestrado Economia. Faculdade de Ciências Econômicas, Universidade Federal de Minas Gerais, 2006.

MACHADO, Ana Flávia; SIMÕES, Rodrigo Ferreira e DINIZ, Sibelle Cornélio. Urban amenities and the development of creative clusters: the case of Brazil. Current Urban Studies, v.1, n. 4, p. 92-101, 2013.

MAGALHÃES, Felipe Nunes Coelho. Da Metrópole à Cidade-Região. Na direção de um novo arranjo espacial metropolitano? Revista Brasileira de Estudos Urbanos e Regionais, v. 10, n. 2, p. 9-27, 2008.

MARTín, María. Queda de braço entre Crivella e escolas de samba ameaça o Carnaval 2018 no Rio. El País, 16 jun. 2017. Disponível em: https://brasil.elpais.com/brasil/2017/06/15/cultura/1497557739 810021.html Acesso em: 24 set. 2017.

MEDEIROS JR, Hélcio; GRAND JR., João; FIGUEIREDO, João Luiz de. A importância da economia criativa no Rio de Janeiro. Coleção Estudos Cariocas, № 11, 2011. Disponível em: http://portalgeo.rio.ri.gov.br/estudoscariocas/download/3067 A importancia da economia criativa no Rio de Janeiro.pdf Acesso em: 14 out. 2019.

O ESTADO DE S. PAULO. Em decadência política, Rio viverá uma década de crise. Estadão, 23 abr. 2017. Disponível em: <http://politica.estadao.com.br/noticias/geral,em-decadencia-politica-rio-vivera-uma-decada-de-crise,70001748272>. Acesso em: 24 set. 2017.

PREFEITURA DO RIO DE JANEIRO. Prefeitura.rio. Prefeitura do Rio de Janeiro website, 2017. Disponível em: <http://www.rio.rj.gov.br/web/guest/conteudos?categoria=\&tag=\&estrutura=STR-NOTICIA>. Acesso em: 22 out. 2017.

PRESTES FILHO, Luiz Carlos e CAVALCANTI, Marcos do Couto (orgs.). Economia da cultura: a força da indústria cultural no Rio de Janeiro. Rio de Janeiro: E-Papers, 2002.

PRETECEILLE, Edmond; VALLADARES, Licia. Favela, favelas: unidade ou diversidade da favela carioca. In: RIBEIRO, Luiz Cesar de Queiroz Ribeiro (org.). O futuro das metrópoles: desigualdade e governabilidade. Rio de Janeiro: Revan: FASE, 2000, p. $375-403$.

RAPS. Plataforma de Sustentabilidade para o Rio de Janeiro. RAPS website, 2016. Disponível em: https://www.raps.org.br/site/wpcontent/uploads/2016/07/2016-7-18 Plataforma-de-Sustentabilidade-Rio-de-Janeiro.pdf . Acesso em: 14 dez. 2016.

ROSSI, Amanda. Congresso aprova decreto de intervenção federal no Rio de Janeiro; entenda o que a medida significa. BBC Brasil, 21 fev. 2018. Disponível em: http://www.bbc.com/portuguese/brasil-43079114 . Acesso em: 15 abr. 2018.

SOARES, Valdomiro. O corte na inovação e as consequências para o país. SEGS, 29 maio 2018. Disponível em:

https://www.segs.com.br/mais/economia/118239-o-corte-na-inovacao-e-as-consequencias-para-o-pais Acesso em: 5 nov. 2019. 
SCOTT, Allen J. Social economy of the metropolis: cognitive-cultural capitalism and the global resurgence of cities. New York: Oxford University Press, 2008.

SCOTT, Allen J. City-regions reconsidered. EPA: Economy and Space, v.0, n.0, p. 1-27, 2019.

VALIATI, Leandro e MOLLER, Gustavo (orgs.). Economia criativa, cultura e políticas públicas. Porto Alegre: Editora UFRGS/CEGOV, 2016. 